\title{
APPLICATION OF SUBSPACE IDENTIFICATION TECHNIQUE TO LONG-TERM SEISMIC RESPONSE MONITORING OF STRUCTURES
}

\author{
Chin-Hsiung Loh $^{1}$ and Shu-Hsien Chao ${ }^{2}$ \\ ${ }^{1}$ Depart emt of Civil Engineering,National Taiwan University, Taipei 10617, Taiwan \\ ${ }^{2}$ National Center for Research on Earthquake Engineering, NARL, Taipei, Taiwan \\ lohc0220@ccms.ntu.edu.tw
}

\begin{abstract}
This paper presents the identification and assessment of the dynamic characteristics of building and bridge structures from the long-term monitoring of seismic response data. Over 40 events of the seismic response data of these structures during the past 10 years were used. To extract the dynamic characteristics of the structures from its seismic response data, the time-domain data-driven subspace identification (SI-DATA) technique is used to extract the system natural frequencies, damping ratios and mode shapes. To enhance the stability of the identified real system poles in using SI-DATA, an algorithm of removing spurious modes is used. Discussion on the identified system dynamic characteristics of the structures under different intensity level of ground excitation is presented. Effect of soil-structural interaction on the identified system natural frequencies and damping ratios by considering either free-field data or basement data as input in subspace identification is also discussed.
\end{abstract}

KEYWORDS : subspace identification, earthquake ground motion, soil-structure interaction, Hilbert amplitude spectrum.

\section{INTRODUCTION}

It is known that the frequency seismic activity may cause the structure subjected to a series of ground motion excitations. The fact that many structural systems exhibit linear behavior at low level of ground motion excitation allows estimation of modal properties from response data. nfortunately, the structural system may deteriorate due to aging problem and may not continue to response in a inear fashion as the level of excitation increase. Therefore, structural damage assessment is one of the important issues in earthquake loss estimation. In order to guarantee the safety, the performance of the structure during the earthquake must be investigated. The modal parameters of the structure system are something of interest. However, the occurrence of the lifetime earthquake load changes with time and because material properties changes with time, either as a direct result of applied loading or because of some deterioration mechanism, the structural dynamic characteristics may change. Consideration needs to be given to situations of the lifetime behavior of the structural system. This paper is to identify the dynamic characteristics of building/bridge subjected to different earthquake excitation during the life time of its operation.

During the past few years, the subspace identification algorithms had been successfully applied on structural system identification. The subspace method can be classified into the Subspace Identification (SI) algorithm which uses both input and output data, and the Stochastic Subspace Identification (SSI) algorithm which is an output-only identification algorithm. In recent years, various versions of subspace method have been used to identify the state space model of linear systems. Each variant corresponds to a different choice of weighting matrices before factorizing the projection matrix. The well-known algorithms include CVA, N4SID, MOESP and IV-4SID (Larimore 1994, Van Overschee 1994, Verhaegen 1994). Good recent overview papers that of the whole class of subspace identification algorithms can be found in the reference (Rao 1992, Van Der 
Veten 1993, Viberg 1994, Van Overschee 1996). Application of subspace identification to damage detection of structure during earthquake had been studied (Weng et al. 2009)

In this study, a series of seismic response of one bridge (a base isolation bridge) and two structures (a 9-story mid-story isolation building and a 9-story RC building) will be studied. Evaluation on the variation of dynamic characteristics of these structures during the period of their service life will be discussed. Through the monitoring or identification of the dynamic characteristics of the structure from each seismic event, one can recognize negative deviation from planned properties of the structures resulting from earthquake-induced damage.

\section{STRONG MOTION INSTRUMENTATION}

For the seismic response monitoring of structures the monitoring system is designed with 200 250 samples/sec and with 16/24-bits resolution. Wired system with AC-63 accelerometer (GeoSIG) was used. The specification of the tri-axial accelerometer AC-63 is $10 \mathrm{Volt} / \mathrm{g}$ and the resolution for AC63 accelerometer is $10^{-5} \mathrm{~g}$. For each structure (either building or bridge) a maximum of 32 channels data logger was design. In this study, three different types of structure were selected (one isolation bridge, one 9-story mid-isolation building and one 7-story RC building. Detail descriptions of these three structures are shown as follows:

A 9-story Mid-Isolation Building : The building was located in the campus of National Taiwan University (Taipei). It was designed as the 9-story mid-story isolation building. A total of 19 isolators were put on top of the first floor underneath each column location. The layout of strong motion accelerometer in this building is shown in Figure 1. A total of 47 seismic events were selected during 2009 and 2013 [Loh et al., 2013].

A 7-story RC building: The building was located in Tai-Chung city. It is a 7-story reinforced concrete building. It was constructed in the year of 1994. The distribution of strong motion accelerometer in this building is shown in Figure 2 and began to operate after 1994. This building was damaged during the Chi-Chi earthquake (1999-9-21). Retrofitting of the structure was completed one year after the Ch-Chi earthquake. A total of 95 seismic events were selected during 1994 and 2013. Response from Chi-Chi earthquake was also included in the analysis.

Chai-Nan River Isolation Bridge: The Chai-Nan River Bridge located at Tainan County in the south-west part of Taiwan. It is a three-span bridge with base-isolation at the top of cap-beam. The distribution of the strong motion accelerometer is shown in Figure 3. The isolators were designed to absorb the energy during earthquake excitation. A total of 63 seismic events were selected during 1999 and 2013. The seismic response of the major aftershock of Ch-Chi earthquake was also included in this study.

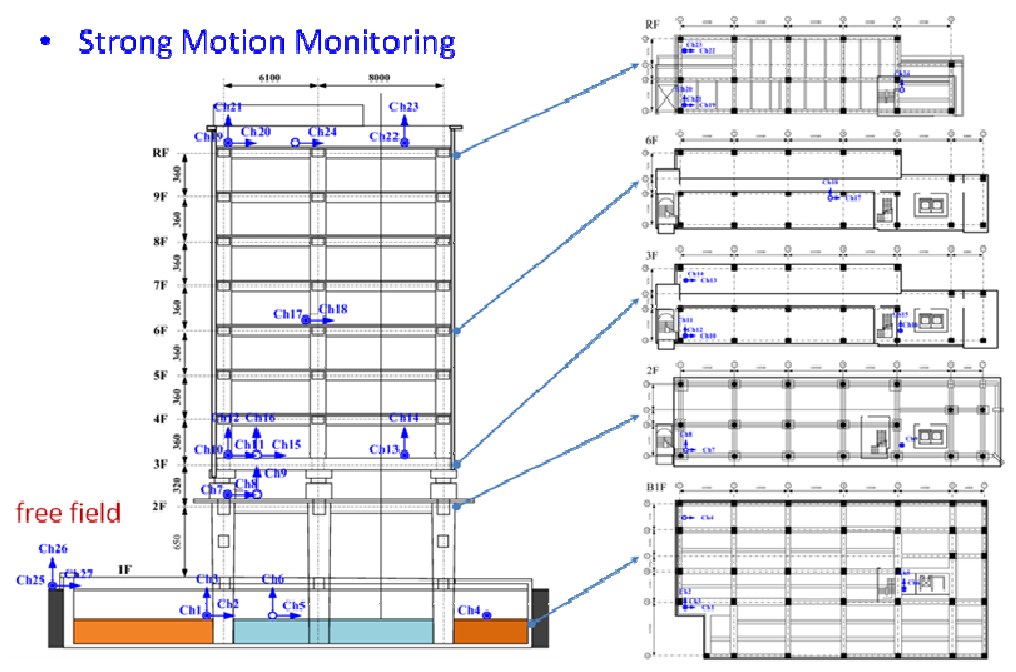

Figure 1. Distribution of strong motion seismograph in the 9-story mid-story isolation building. 

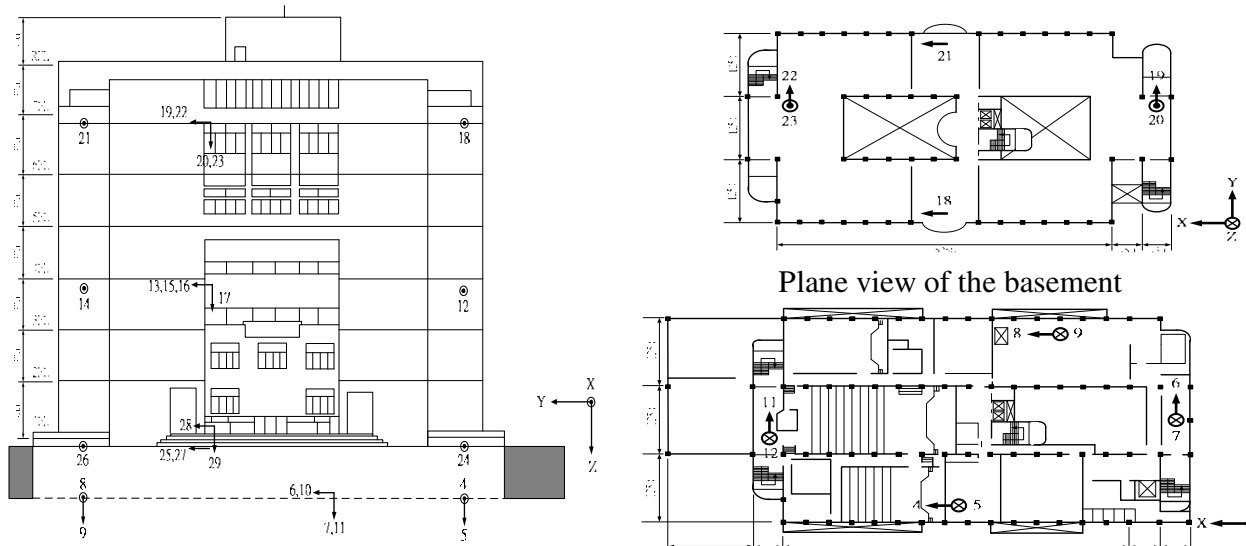

Plane view of the basement

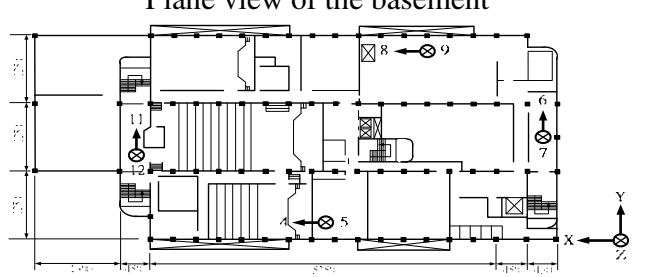

Figure 4: Distribution of strong motion seismograph in a 7-story RC Building.
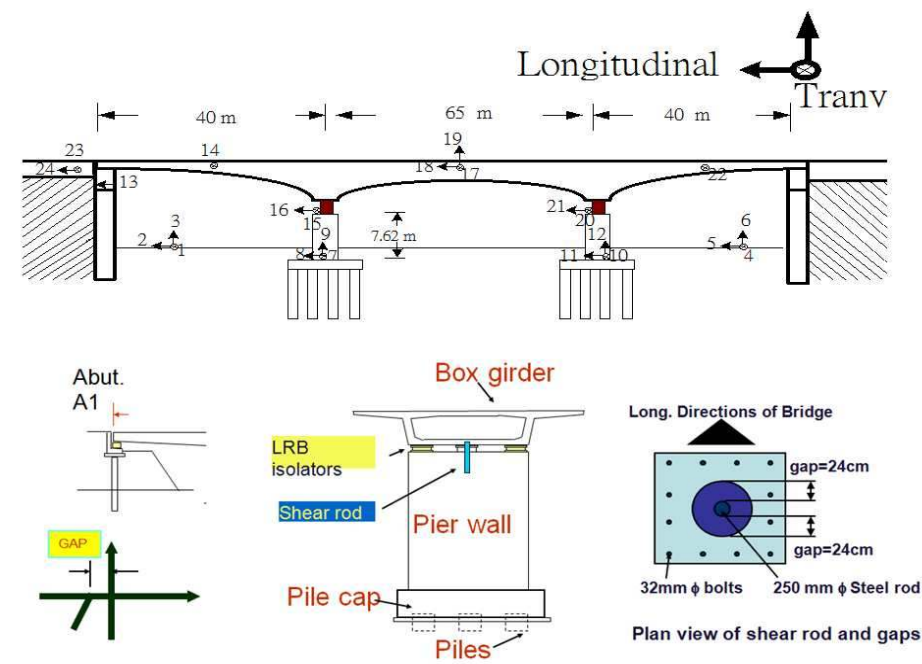

Plan view of shear rod and gaps

Figure 3: Distribution of strong motion seismograph in Chia-Nan River bridge. Detail location of isolator is also shown.

\section{DATA-DRIVEN SUBSPACE IDENTIFICATION}

To identify the dynamic characteristics of structure from its seismic response data, the data-driven subspace identification technique was used. Consider a discrete-time cokmbined deterministicstochastic system which combined the stochastic system and the deterministic system.

$$
\begin{gathered}
\mathbf{X}_{k+1}=\mathbf{A}_{d} \mathbf{X}_{k}+\mathbf{B}_{\mathrm{d}} \mathbf{u}_{\mathrm{k}}+\mathbf{w}_{\mathrm{k}} \\
\mathbf{y}_{\mathrm{k}}=\mathbf{C}_{\mathrm{c}} \mathbf{X}_{\mathrm{k}}+\mathbf{D}_{\mathrm{c}} \mathbf{u}_{\mathrm{k}}+\mathbf{v}_{\mathrm{k}}
\end{gathered}
$$

With $\mathbf{X}_{\mathbf{k}}=\mathbf{X}_{\mathbf{k}}^{\mathbf{d}}+\mathbf{X}_{\mathbf{k}}^{\mathbf{s}}, \mathbf{y}_{\mathbf{k}}=\mathbf{y}_{\mathbf{k}}^{\mathbf{d}}+\mathbf{y}_{\mathbf{k}}^{\mathbf{s}} \cdot \mathbf{X}_{\mathbf{k}}^{\mathbf{d}} \in \mathfrak{R}^{2 n \times 1}$ is the state vector in deterministic system and $\mathbf{y}_{\mathbf{k}}^{\mathbf{d}} \in \mathcal{R}^{l \times 1}$ is the output vector, $\mathbf{w}_{\mathbf{k}} \in \mathcal{R}^{2 n \times 1}, \mathbf{v}_{\mathbf{k}} \in \mathcal{R}^{l \times 1}$ are white noises. The superscript "d" means "deterministic" and it implicates that the input/output data can be measured without any noise contamination, and the superscript "s" means "stochastic" and it implicates that the system is excited by stochastic component. First, the output Hankel matrix can be constructed from the output data. Assign $\mathbf{i}$ is the number of block rows which is a user-defined index and must be larger than the order $2 \mathrm{n}$ of the system. $\mathrm{j}$ is the number of block columns of the output Hankel matrix, as shown below: 


$$
\left[\begin{array}{l}
\mathbf{Y}_{\mathrm{p}}^{\mathrm{s}} \\
\hline \mathbf{Y}_{\mathrm{f}}^{\mathrm{s}}
\end{array}\right] \equiv\left[\begin{array}{cccc}
\mathbf{y}_{1}^{\mathrm{s}} & \mathbf{y}_{2}^{\mathrm{s}} & \cdots & \mathbf{y}_{\mathrm{j}}^{\mathrm{s}} \\
\mathbf{y}_{2}^{\mathrm{s}} & \mathbf{y}_{3}^{\mathrm{s}} & \cdots & \mathbf{y}_{\mathrm{j}+1}^{\mathrm{s}} \\
\vdots & \vdots & \ddots & \vdots \\
\mathbf{y}_{\mathrm{i}}^{\mathrm{s}} & \mathbf{y}_{\mathrm{i}+1}^{\mathrm{s}} & \cdots & \mathbf{y}_{\mathrm{i}+\mathrm{j}-1}^{\mathrm{s}} \\
\hline \mathbf{y}_{\mathrm{i}+1}^{\mathrm{s}} & \mathbf{y}_{\mathrm{i}+2}^{\mathrm{s}} & \cdots & \mathbf{y}_{\mathrm{i}+\mathrm{j}}^{\mathrm{s}} \\
\mathbf{y}_{\mathrm{i}+2}^{\mathrm{s}} & \mathbf{y}_{\mathrm{i}+3}^{\mathrm{s}} & \cdots & \mathbf{y}_{\mathrm{i}+\mathrm{j}+1}^{\mathrm{s}} \\
\vdots & \vdots & \ddots & \vdots \\
\mathbf{y}_{2 \mathrm{i}}^{\mathrm{s}} & \mathbf{y}_{2 \mathrm{i}+1}^{\mathrm{s}} & \cdots & \mathbf{y}_{2 \mathrm{i}+\mathrm{j}-1}^{\mathrm{s}}
\end{array}\right] \in \mathbb{R}^{2 l i \times j}
$$

The input data $\mathbf{u}_{\mathrm{k}}$ can also be arranged in the Hankel matrix:

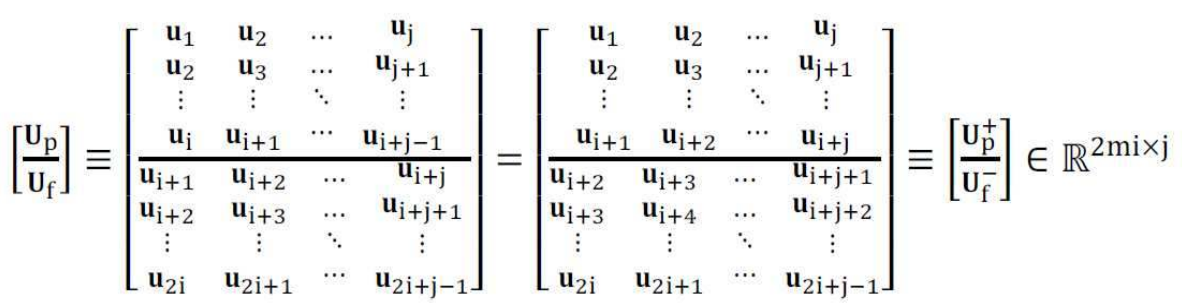

where $\mathbf{U}_{\mathrm{p}} \in \mathbb{R}^{\mathrm{mi} \times \mathrm{j}}$ is the past input Hankel matrix and $\mathbf{U}_{\mathrm{f}} \in \mathbb{R}^{\mathrm{mixj}}$ is the future input Hankel matrix. The matrices $\mathbf{U}_{\mathrm{p}}^{+} \in \mathbb{R}^{\mathrm{m}(\mathrm{i}+1) \times \mathbf{j}}$ and $\mathbf{U}_{\mathrm{f}}^{-} \in \mathbb{R}^{\mathrm{m}(\mathrm{i}-1) \times \mathrm{j}}$ are defined by shifting the border between $\mathbf{U}_{\mathrm{p}}$ and $\mathbf{U}_{\mathrm{f}}$ one block row down. Moreover, two special Hankel matrices consisting of both input and output data are defined as (Willems 1987):

$$
\boldsymbol{\Xi}_{\mathrm{p}}=\left[\begin{array}{l}
\mathbf{U}_{\mathrm{p}} \\
\mathbf{Y}_{\mathrm{p}}
\end{array}\right] \in \mathbb{R}^{(\mathrm{m}+\mathrm{l}) \mathrm{i} \times \mathrm{j}}, \boldsymbol{\Xi}_{\mathrm{p}}^{+}=\left[\begin{array}{c}
\mathbf{U}_{\mathrm{p}}^{+} \\
\mathbf{Y}_{\mathrm{p}}^{+}
\end{array}\right] \in \mathbb{R}^{(\mathrm{m}+\mathrm{l}+2) \mathrm{i} \times \mathrm{j}}
$$

When only the modal properties (i.e. natural frequency, damping ratio and mode shape) of the structure are needed The "Multivariable Output-Error State sPace" algorithm (MOESP) is employed to extract the column space of the extended observability matrix $\boldsymbol{\Gamma}_{\mathbf{i}}$ from the LQ-decomposition of the Hankel matrix [Verhaegen, 1994].

$$
\begin{aligned}
& \text { mi }(m+1) i \quad l i \quad j
\end{aligned}
$$

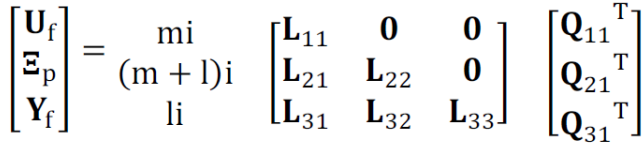

$$
\begin{aligned}
& \left(\mathbf{Y}_{\mathrm{f}} / \mathbf{U}_{\mathrm{f}} \Xi_{\mathrm{p}}\right) / \mathbf{U}_{\mathrm{f}}{ }^{\perp}=\boldsymbol{\Gamma}_{\mathrm{i}} \widetilde{\mathbf{X}}_{\mathrm{i}} / \mathbf{U}_{\mathrm{f}}{ }^{\perp}=\mathbf{L}_{32} \mathbf{Q}_{21}{ }^{\mathrm{T}}
\end{aligned}
$$

Column space $\left(\mathbf{L}_{32}\right)=$ column space $\left(\Gamma_{\mathrm{i}}\right)$

Once $\mathbf{L}_{32}$ are obtained from the LQ decomposition of the Hankel matrix, the system parameters can be determined form the singular value decomposition:

$$
\begin{gathered}
\mathbf{L}_{32}=\mathbf{U S V}^{\mathrm{T}}=\left[\begin{array}{ll}
\mathbf{U}_{1} & \mathbf{U}_{2}
\end{array}\right]\left[\begin{array}{cc}
\mathbf{S}_{1} & \mathbf{0} \\
\mathbf{0} & \mathrm{S}_{2}
\end{array}\right]\left[\begin{array}{c}
\mathbf{V}_{1}^{\mathrm{T}} \\
\mathbf{V}_{2}^{\mathrm{T}}
\end{array}\right] \approx \mathbf{U}_{1} \mathbf{S}_{1} \mathbf{V}_{1}^{\mathrm{T}} \\
\left.\boldsymbol{\Gamma}_{\mathbf{i}}=\mathbf{U}_{1} \text { (if } \mathrm{N}=2 \mathrm{n}\right)
\end{gathered}
$$

The system matrix $\mathbf{A}_{\mathrm{d}}$ and the measurement matric $\mathbf{C}_{\mathrm{c}}$ can be determined from $\boldsymbol{\Gamma}_{\mathrm{i}}$ and the modal properties of the system can finally be identified.

In this study, the removing spurious mode method is used overcome the drawbacks of using stabilization diagram (Zhang et al. 2012). It starts from the determination of the system matrix $\mathbf{A}$. Two different approaches are proposed to calculate the system matrix $\mathbf{A}$ as:

$$
\mathbf{A}_{1}=\mathbf{O}[1: n(L-1),:]^{\ell} \mathbf{O}[n+1: n L,:]
$$

$$
\mathbf{A}_{2}=\left\{\mathbf{O}[1: n(L-1),:]^{T} \mathbf{O}[n+1: n L,:]\right\}^{-1}\left\{\mathbf{O}[1: n(L-1),:]^{T} \mathbf{O}[1: n(L-1),:]\right\}
$$


where $L$ is the order of Toeplitz matrix, $\mathrm{n}$ is the number of outputs and " " " denotes the matrix pseudo-inverse. From these two different approaches, one can derive two different groups of modal properties based on the same assumed system order and the size of data Hankel matrix. If a certain mode is identified simultaneously both by these two approaches, it can be identified as a real system mode. By comparing the modal properties of these two groups, one can identify and remove the spurious modes. In real application, different threshold are defined to check the consistency of the modal properties derived from two approaches:

$$
\left|f_{1}-f_{2}\right|<f_{\text {threshold }}, \quad\left|\xi_{1}-\xi_{2}\right|<\xi_{\text {threshold }} \text { and } \quad\left|\frac{\boldsymbol{\psi}_{1}^{\mathrm{T}} \boldsymbol{\Psi}_{2}}{\left\|\boldsymbol{\Psi}_{1}\right\|^{0.5}\left\|\boldsymbol{\Psi}_{2}\right\|^{0.5}}\right|>M A C_{\text {threshold }}
$$

where $f_{1}, \xi_{1}$ and $\boldsymbol{\psi}_{1}$ are modal frequency, damping ratio and mode shape a certain mode evaluated from approach $1 ; \mathrm{f}_{2}, \xi_{2}$ and $\psi_{2}$ are modal frequency, damping ratio and mode shape of a certain mode evaluated from approach $2 ; \mathrm{f}_{\text {threshold }}, \xi_{\text {threshold }}$ and $M A C_{\text {threshold }}$ are threshold levels for frequency, damping ratio and mode shape. In this study the threshold are assumed as $0.02 \mathrm{~Hz}, 0.01$ and 0.9 respectively. The variance of the estimated modal parameters can be quantified easily by performing the analysis of this approach through using different size of the data Hankel matrix and the system order.

\section{RESULTS OF IDENTIFICATION}

Analysis of the 9-story isolation building Subspace identification technique is used by considering data collect from the seismographs in the basement as input and the response from the other seismographs as output. Figure $\mathbf{4}$ shows the distribution of the identified first three system natural frequencies of each seismic event. The peak ground acceleration which corresponds to each seismic event is also shown. It is observed that the earthquake excitation level (input PGA) is not quite large ( $<28 \mathrm{gal})$ among all the seismic events but the variation of the identified system natural frequencies is quite significant. From Figures $\mathbf{5 a}$ and $\mathbf{5 b}$ is is observed that the identified system natural frequencies decrease with increasing input PGA, while the damping ratio increases with the decreasing system natural frequency. Since the building is designed with mid-isolation system (isolator with very low yield deformation), the influence of isolation system to the response of super-structure is obvious. The amplification ratio (between input and response) is about 3.0 for input PGA less than 5.0 gal. On the contray, less amplification rati is observed for input PGA larger than 15 gal, as shown in Figure 5c.

Analysis of a 7-story RC building In applying the SI-DATA method to the CE-NCHU building data measured from channel 4, 6, 8 and 10 are regarded as inputs and channel 12-16, 18, 19, 21 and 22 are regarded as outputs. First, the identified system natural frequencies were plotted with respect to each event, as shown in Figure 6. Variation of the identified modal frequencies changes with respect to seismic event is very obvious for this building, particularly before and after Sept 21, 1999 (Chi-Chi earthquake). Before the Chi-Chi earthquake, the identified building modal frequencies is about $3.0 \mathrm{~Hz}$ in both longitudinal and transverse directions. Since the building was damaged by ChiChi earthquake, the system modal frequencies were reduced to about $2.0 \mathrm{~Hz}$ because of the damage in the first floor. Restoration of the building had been completed one year later after the Chi-Chi earthquake. The identified system natural frequencies went back to about $2.70 \mathrm{~Hz}$. The change of modal frequency before and during the Chi-Chi earthquake is obvious. One can separate the identified system natural frequencies into two groups: one group is before the Chi-Chi earthquake and the other group is after the restoration, as shown in Figure 7. During 1994 and 1998 the identified system natural frequencies are about $3.0 \mathrm{~Hz}$ and almost no change with respect to different seismic event, while after restoration (after year of 2000) the system natural frequency is about $2.70 \mathrm{~Hz}$ but decrease with increasing earthquake excitation level. 

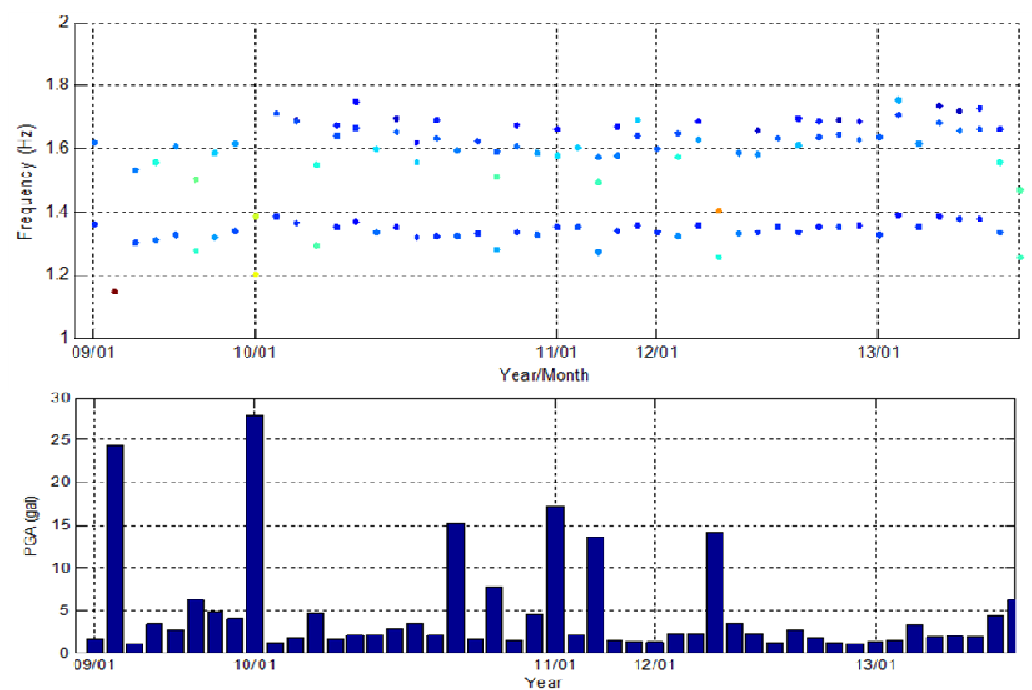

Figure 4. (a) Plot the identified natural frequencies of the mid-story isolation building with respect to each seismic event, (b) The input PGA for each seismic event is also shown.
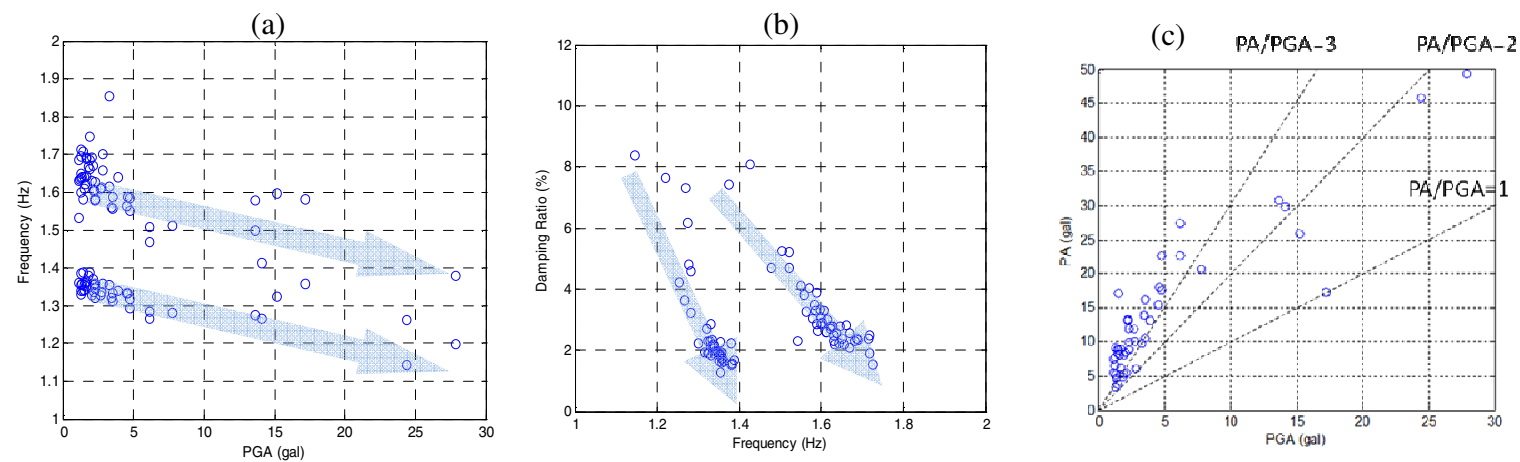

Figure 5. The relationship between, (a) the identified system natural frequencies $\left(1^{\text {st }} \& 2^{\text {nd }}\right.$ modes $)$ and PGA, (b) The identified system damping ratio and natural frequencies, (c) PGA and maximum peak acceleration of the structural response
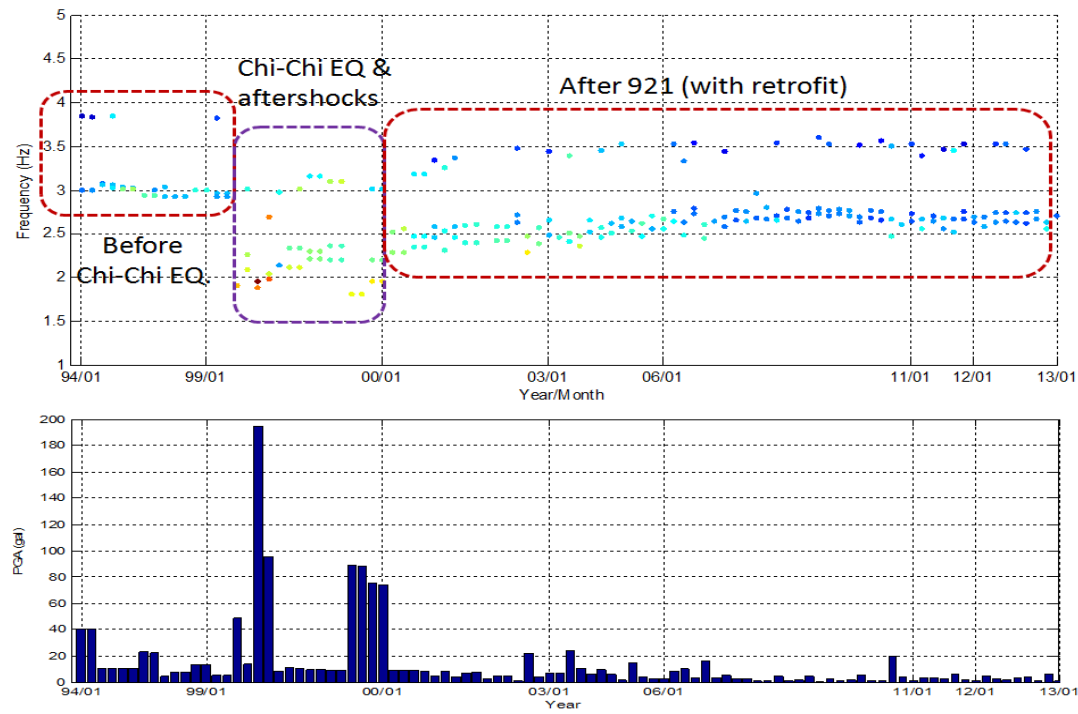

Figure 6: (a) Plot the identified system natural frequencies of the 7-story building with respect to each seismic event, (b) The input PGA for each seismic event is also shown. 

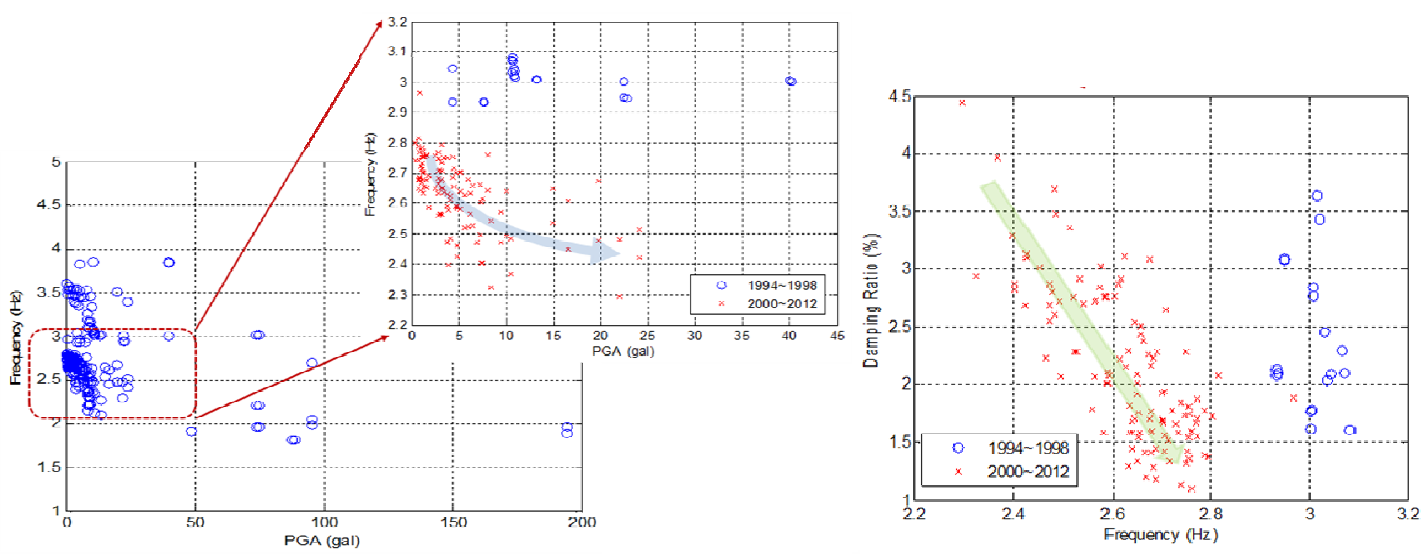

Figure 7: The relationship between the identified modal frequency and PGA from data between 1994 and 2012. Two group of the identified modal frequencies and damping ratios can be defined: before 1999 and after 2000.

Analysis of the base-isolation bidge In this case study only transverse modal properties will be discussed. Consider Ch.7 and Ch.10 as input and Ch.14, Ch.15, Ch.17, Ch.20 and Ch.22 as output (transverse direction) in SI-DATA, the identified modal frequencies of the bridge (in transverse direction) is shown in Figure 8. It is also observed that the identified system damping ratio decrease with the increase of system natural frequency which indicated the performance of the bridge isolation system, as shown in Figure 9.

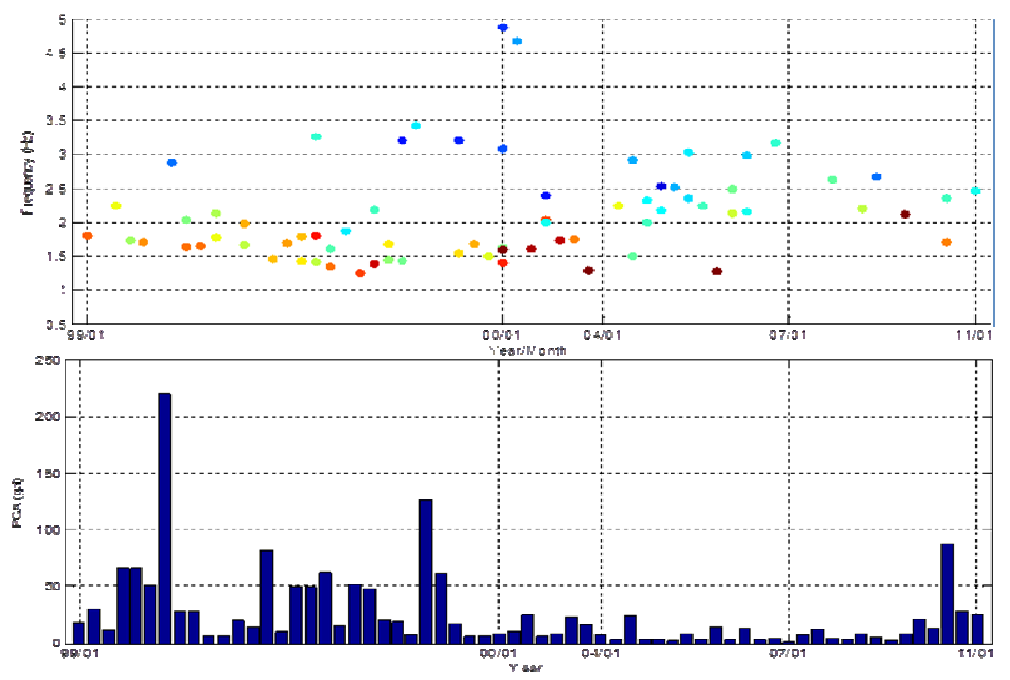

Figure 8: (a) Plot the identified modal frequencies of Chia-Nan river bridge with respect to each seismic event, (b) The input PGA for each seismic event is also shown.

(a)

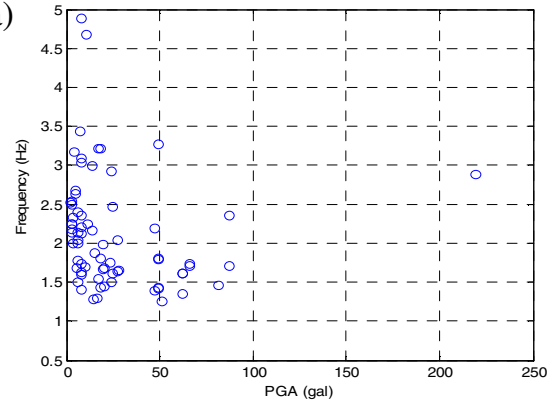

(b)

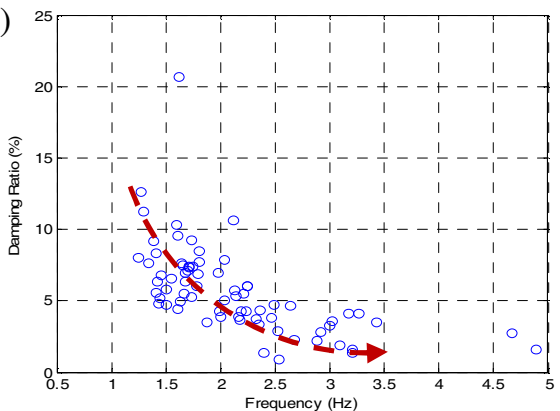

Figure 9: (a) Plot the relationship between, (a) the idenntified modal frequencies and dapming ratios of the Chi-Nan river bridge, (b) the idenntified modal frequencies and PGA. 


\section{DISCUSSION AND CONCLUSION}

System identification of large structures such as bridges and buildings has received considerable attention. Through identification, one can determine whether the properties of the observed structures are changing over time. In the earthquake prone area, such as Taiwan, structural system identification using seismic response data is one of the important tolls for structural health assessment. In this study the data-driven subspace identification using both input and output data was applied to extract the modal properties of three specific structures during their life time services. Discussion on the identified modal frequencies and damping ratios change with respect to different intensity level of earthquake excitation was made:

(1) In SI-DATA the input ground motion for identification one can use response measurement from either free-field or basement. The effect of soil-structure interaction on the influence of the identified modal frequencies and damping ratios can be observed by using different set of input motion. From this study, it is observed that the influence of soil-structure interaction on the dynamic characteristics of the structure is significant. It shows that the damping ratio may increase $25 \%$ (damping ration from $8.1 \%$ to $10.2 \%$ ) by considering the effect of soil-structure interaction for case of large sesimic event for the 9-story mid isolation building.

(2) Through the continuous monitoring of the modal parameters of the strucutre event by event, one can detect the abnormal situation of the structural response under particular earthquake excitation. A better understanding on buildinng seismic response can be achieved.

\section{ACKNOWLEDGEMENTS}

The authors gratefully acknowledge the supports from both National Science Council of the Republic of China, Taiwan (under Contract No. NSC 101-2811-M-002-061) and Central Weather Bureau (Taiwan) under grant number MOTC-CWB-102-E-10.

\section{REFERENCES}

[1] Larimore, W. E. "The Optimality of Canonical Variate Identification by Example," Proc. of SYSID '94, 4-6 July, Copenhagen, Denmark, 2, 151-156. 1994.

[2] Loh, C.H., Weng, J.H., Chen, C.H. and Lu, K.C. "System Identification of Mid-story Isolation Building Using Both Ambient \& Earthquake Response Data," Structural Control \& Health Monitoring, Vol.20, 139-155. 2013.

[3] Rao, B., Arun, K. S. "Model Based Processing of Signals: A State Space Approach," Proc. of the IEEE, 80(2), 283-309. 1992.

[4] Van Overschee, P. \& De Moor, B. "N4SID: Subspace Algorithms for the Identification of Combined Deterministic-Stochastic Systems," Automatica, 30(1), 75-93. 1994.

[5] Verhaegen, M. "Identification of the deterministic part of MIMO state space models given in innovations from input-output data," Automatica, 30(1), 61-74. 1994.

[6] Van Der Veen, A., Deprettere, E. F., Swindlehurst, A. L. "Subspace-Based Signal Analysis Using Singular Value Decomposition," Proc. of the IEEE, 81(9), 1277-1308. 1993.

[7] Viberg, M. "Subspace Methods in System Identification," Proc. of SYSID '94, 4-6 July, Copenhagen, Denmark, 1, 1-12. 1994.

[8] Weng, J-H., Loh, C.H. and Yang, J.N. "Experimental Study of Damage Detection by Data-Driven Subspace Identification and Finite Element Model Updating," J. of Structural Engineering, ASCE, 2009.

[9] Willems, J. "From time series to linear systems," Automatica, Part I: 22(5), 561-580, 1986; Part II: 22(6), 675-694, 1986; Part III: 23(1), 87-115, (1987).

[10] Zhang, G., Tang, B., Tang, G. "An improved stochastic subspace identification for operational modal analysis," Measurement, vol. 45, 1246-1256. 2012. 